\title{
Las Escuelas Normales Superiores en Colombia: doscientos años de historia entre retos y desafíos (1821-2021)
}

\author{
José Oliden Muñoz Bravo ${ }^{1}$ \\ Escuela Normal Superior del Mayo, Colombia
}

Recepción: 23/04/2020

Evaluación: 30/04/2020

Aceptación: 10/05/2020

Artículo de Investigación-Científica

DOI: https://doi.org/10.22267/rhec.202525.79

\section{Resumen}

Este artículo se caracteriza por seguir el proceso histórico de las escuelas normales en Colombia, en el que se presenta un análisis de la relación entre la práctica pedagógica, investigación, formación docente, con revisión de los diferentes niveles educativos trazados a través de la Historia, donde se demuestra cuál es el papel que se ha cumplido en estos doscientos años; los maestros ponen en juego sus saberes en torno a la enseñanza, a los aprendizajes propios de sus estudiantes; las enseñanzas han sido tradicionalmente uno de los elementos más valorados en la formación de maestros, lo han sido tanto por los futuros maestros en su formación inicial como por los maestros en ejercicio, lo que demuestra el auténtico conocimiento que se precisa para llevar a cabo la formación de un auténtico profesional de la educación.

Las metas de los maestros se centran en sus clases y las aulas son laboratorios y se diseñan para enseñar a enseñar, donde supone la exigencia de los programas que se van a llevar a cabo en las prácticas que configuran en cada persona su aprendizaje como maestro. El maestro, ese maestro que logra trascender sus límites y conquistar otros espacios en el universo de la formación, goza con el resultado de sus discípulos, aunque queden en el camino huellas de injusticia e ingratitud.

1 Docente en la Escuela Normal Superior del Mayo, Colombia. Doctor en Ciencias de la Educación. Grupo de investigación: GIDEP. Linea de investigación: Pedagogia y didactica. Correo electrónico: jolidemu65@gmail.com. ㄴ) https://orcid.org/0000-0003-0366-6695 
Formar para la docencia ha llevado a las Escuelas Normales a asumir el reto de acortar la distancia entre la formación teórica que se recibe en estas instituciones, las experiencias prácticas que se obtienen en las escuelas de educación básica y las demandas sociales, culturales y tecnológicas que la sociedad impone constantemente. La práctica docente debe ser praxis pedagógica, porque es creación, es transformación y es posicionamiento del sujeto frente a la docencia; consecuentemente, porque a través de ella el sujeto tiene la posibilidad de resignificar y dar otro sentido a la práctica cotidiana que observa, que analiza y en la que se encuentra inserto.

La formación de los maestros en Colombia ha sido potestad de las Escuelas Normales Superiores y las Facultades de Educación de las universidades. Unas y otras han tenido a lo largo de la Historia las instituciones autorizadas para orientar la práctica pedagógica, la investigación y la formación integral del docente como fundamento del saber específico de un verdadero educador.

Palabras clave: Educación Rural; Escuela Normal Superior; Formación de docentes; Práctica Pedagógica.

\title{
Escuelas Normales Superiores in Colombia: two hundred years of history between challenges and defiance (1821-2021)
}

\begin{abstract}
This article is characterized by following the historical process of teacher training schools in Colombia, in which an analysis of the relationship between pedagogical practicum, research and teacher training is presented, with a review of the different educational levels traced throughout history, showing the role that has been fulfilled in these two hundred years; teachers bring into play their knowledge about teaching, about their students' own learning; teaching has traditionally been one of the most valued elements in teacher training, both by future teachers in their initial training and by pre-service teachers, which shows the authentic knowledge that is required to carry out the training of a true education professional.
\end{abstract}


The goals of teachers are centered in their classes and their classrooms which are a sort of laboratories and are designed to teach how to teach, where it is possible to trace the demand of the programs to be carried out in the practicum that shape each person's learning as a teacher. The teacher, who manages to transcend his limits and conquer other spaces in the universe of teacher training, enjoys the work of his disciples, even though there are traces of injustice and ingratitude along the way.

Teacher training has led Escuelas Normales Superiores to assume the challenge of shortening the distance between the theoretical training received in these institutions, the practical experiences obtained in basic education schools and the social, cultural and technological demands that society constantly imposes. Teaching practicum should be pedagogical praxis, because it is creation, transformation and positioning of the subject in relation to teaching; consequently, because the subject has the possibility of giving another meaning to the daily practice that pre-service teachers observe, analyze and in which they are part of.

Teacher training in Colombia has been the responsibility of Escuelas Normales Superiores and the Faculties of Education from public and private universities in Colombia. Throughout history, both have been the authorized institutions to guide the pedagogical practicum, educational research and comprehensive teacher training as the foundation of the specific knowledge of a true educator.

Keywords: Rural education; Escuela Normal Superior; teacher training; educational practicum.

\section{As Escolas Normais Superiores na Colômbia: duzentos anos de história entre desafios e desafios (1821-2021)}

\section{Resumo}

Este artigo se caracteriza por seguir o processo histórico das escolas normais na Colômbia, no qual se apresenta uma análise da relação entre a prática pedagógica, a pesquisa, a formação docente, com uma revisão 
dos diferentes níveis educacionais traçados ao longo da História, onde se mostra o que é o papel que vem cumprindo nestes duzentos anos; os professores colocam seus conhecimentos em prática em torno do ensino, da própria aprendizagem dos alunos; $\mathrm{O}$ ensino tem sido tradicionalmente um dos elementos mais valorizados na formação docente, tanto pelos futuros professores na sua formação inicial como pelos docentes em exercício, o que demonstra o saber autêntico que se exige para realizar a formação de um verdadeiro profissional educativo.

Os objetivos dos professores estão centrados nas suas aulas e as salas de aula são laboratórios e destinam-se a ensinar a ensinar, onde as exigências dos programas que vão se realizar nas práticas que configuram a sua aprendizagem docente em cada pessoa. O professor, aquele professor que consegue transcender seus limites e conquistar outros espaços no universo da formação, goza do resultado de seus discípulos, ainda que no caminho permaneçam vestígios de injustiça e ingratidão.

A formação para a docência tem levado as Escolas Normais a assumir o desafio de encurtar a distância entre a formação teórica recebida nessas instituições, as experiências práticas obtidas nas escolas de educação básica e as demandas sociais, culturais e tecnológicas que a sociedade constantemente impõe. A prática docente deve ser práxis pedagógica, porque é criação, é transformação e é posicionamento do sujeito diante do ensino; conseqüentemente, porque por meio dela o sujeito tem a possibilidade de ressignificar e dar outro sentido à prática cotidiana que observa, que analisa e na qual está inserido.

A formação de professores na Colômbia tem estado a cargo das Escolas Superiores Normais e das Faculdades de Educação das universidades. Ao longo da história, ambos tiveram as instituições autorizadas a orientar a prática pedagógica, a pesquisa e a formação integral do professor como alicerce dos saberes específicos de um verdadeiro educador.

Palavras-chave: Educação Rural; Escola Normal Superior; Formação de Professores; Prática Pedagógica. 


\section{Introducción}

La creación de las Escuelas Normales destinadas a la formación de maestros en Colombia, en la segunda década del siglo XIX, formó parte de una política de Estado para resolver problemas de orden social, cultural, económico y científico, con adelanto de programas educativos de acuerdo con sus necesidades y la influencia de corrientes ideológicas europeas y norteamericanas. La intención principal fue elevar la capacidad pedagógica de los maestros en busca de solucionar el problema del bajo número de escuelas.

Para el estudio de las Escuelas Normales en Colombia² desde 1821, es importante tener como referente el ordenamiento jurídico que definió el origen y sentido de estas instituciones. En sus orígenes, las leyes, resoluciones, decretos, buscaron reformar el servicio educativo de acuerdo a su funcionamiento para el servicio de las comunidades educativas, reformas que se han implementado con el único propósito de mejorar la enseñanza-aprendizaje para que los maestros asuman con criterio el trabajo pedagógico en cada escuela.

La investigación de tipo histórico tiene como tema central mostrar el logro alcanzado por las Escuelas Normales Rurales en estos doscientos años de trabajo pedagógico, como instituciones pioneras en la formación de docentes, con el propósito de formar a los niños del sector rural con implementación de metodologías, como el Plan Lancaster y Pestalozzi.

Por lo tanto, en este artículo, se trata de dar a conocer la forma en que el maestro viene aportando estrategias y metodologías que, a través del currículo, han estructurado conocimientos a los niños para llevar a este país a algo diferente, con respecto a la política pública educativa diseñada por el Ministerio de Educación Nacional.

Además, se necesita tomar el testimonio de una maestra rural de tres años de formación: Lucrecia Muñoz Palacios, quien, a través de su experiencia, relata cómo fue su formación y cómo educaban a los niños en

2 Sobre el tema véase: Diego Quintero Timaná, "Formación docente en Educación Para La Paz, en la Escuela Normal Superior del Municipio de La Cruz - Nariño", Revista Historia de la Educación Colombiana. Vol. 24. No 24 (2020). https://doi.org/10.22267/ rhec.202424.73; Claudia Figueroa y Carlos Londoño Ramos. "De La Escuela Normal Superior de Colombia Al Instituto Caro y Cuervo. Un aporte histórico cultural a la educación colombiana (1936-1951). Revista Historia de la Educación Colombiana. Vol. 18. N $^{\mathrm{o}} 18$ (2015): 71-95, https://doi.org/10.22267/rhec.151818.29 
su tiempo para superar los problemas de lectura y escritura, conocimientos matemáticos, religión y formación en valores.

Jurídicamente las Escuelas Normales se crearon en el Congreso de Cúcuta, con la Ley 1, de agosto 6 de 1821, en la que se tomaron decisiones políticas acerca del papel de la instrucción pública en la formación de ciudadanos, con el fin de formar maestros para enseñar en las escuelas del país.

Las técnicas de acopio de información utilizadas fueron la entrevista, la historia de vida y la revisión de documentos históricos, donde se hace un trabajo muy detallado con maestras rurales, quienes logran expresar su sentido e ideología propia, según su desempeño y experiencia pedagógica aplicada en cada escuela primaria.

La acreditación de las Normales surge en los años 90 del siglo XX, en busca de garantizar la calidad en la formación de los futuros maestros, con la práctica pedagógica investigativa y la autoevaluación como los criterios que el Ministerio de Educación utilizaría para garantizar el mejoramiento continuo y la calidad educativa.

\section{Orígenes de las Escuelas Normales en Colombia y temas conexos}

En los primeros años de vida independiente, en la época republicana, en el Congreso de Cúcuta, mediante la Ley 1, del 6 de agosto de 1821, se tomaron decisiones políticas acerca del papel de la instrucción pública en la formación de los ciudadanos, se autorizó la fundación de Escuelas Normales y el general Santander, en 1822, creó la primera Escuela Normal por el método lancasteriano en Santafé de Bogotá, bajo la dirección del franciscano payanés Fray Sebastián de Mora. Sin embargo, estas instituciones tuvieron una vida efímera y contradictoria.

Se requiere mencionar que en 1822 se había creado, en Bogotá, la primera Escuela Normal del país, con el objeto de formar profesores, normalizar las prácticas de enseñanza y difundir el Sistema de enseñanza mutua, iniciativa impulsada por Simón Bolívar y Francisco de Paula Santander, convencidos de los beneficios de un sistema que permitía "a un solo maestro enseñar a mil niños al tiempo, los rudimentos de la moral, la escritura y el cálculo", según Vasco; según Sáenz et al., La Escuela Normal surgió, entonces, con la función de "normalizar, uniformar el lenguaje, las formas de pensar y de sentir" (70). 
Cuando aparecen las primeras Escuelas Normales, tenían como propósito la formación de maestros para la enseñanza en las escuelas que se abrirían a dar instrucción a futuros maestros de primaria; el nombre de Escuela Normal, según Herrera (1990), "tiene su origen en la idea de normalizar o estandarizar la información a los educadores que después irán a formar a los niños" (14), de ahi el término Normal, que plantea una serie de reglamentos acerca del método, en primera instancia, y de la formación del maestro para la primera infancia, para proyectarse luego a las prácticas pedagógicas.

En la época colonial no había maestros y esa labor la cumplían los eclesiásticos; el maestro empieza a aparecer cuando esta figura se va desagregando (al lado del cura aparece el juez, el maestro, y se van diferenciando); la primera aparición del maestro es la de aquel que toca las puertas, para vender el conocimiento. (Bohórquez, 1956, 38).

La disposición para crear las Escuelas Normales se contenía en su Artículo 15 (Ley 6 de agosto de 1821), aprobada para establecer escuelas de primeras letras para los niños de ambos sexos.

La expansión de las Escuelas Normales para la formación de maestros tuvo como propósito general la integración nacional, el conocimiento de nuevos modelos sociales, filosóficos y la aplicación de tipo pedagógico, según Zuluaga (1996), lo que permitió la diversificación de la enseñanza y la formación de maestros, para estructurar una sociedad con nuevos ideales, que aseguraran un campo formativo para la nación. Según él:

Las escuelas normales debían formar a los maestros para enseñar en las escuelas que se fundarían, al menos una en todas las ciudades, villas, parroquias y pueblos que tuviesen cien o más vecinos. En ellas, la educación impartida por el maestro sería "la más generalmente difundida como que es la fuente de todos los demás conocimientos humanos (266).

Sin lugar a dudas, la Escuela Normal, como institución para formar maestros y promover un saber sobre la enseñanza, se inició con las reformas de Ospina. En octubre de 1844, se inauguró la Escuela Normal del distrito de Bogotá, en un edificio construido de acuerdo con las normas del método lancasteriano. El método dejó de ser el único conocimiento pedagógico de los maestros. En este sentido, se redactó un programa de Pedagogía, el primero que se enseñaba en el país, que introdujo un discurso sobre las 
facultades del hombre, destinado a los maestros. Un paso muy importante, que consolidó a la Escuela Normal, fue haberla separado de la escuela parroquial; es decir, haberle dado identidad como institución.

Estas condiciones llevaron a la Escuela Normal a ser una institución para formar maestros mediante un método de enseñanza que, lejos de fortalecer su carácter de institución del saber pedagógico, la convirtió simplemente en un polo de difusión de la enseñanza mutua con una proyección muy simple en el oficio de maestro. La reforma, según Ospina (1844) iba a transformar esta situación (33).

Durante el Siglo XX, se puede destacar que el gobierno nacional dispuso, en 1903, que en cada Departamento se abriera una escuela para varones y otra para mujeres, las que deberían contar con una escuela primaria anexa para los ejercicios prácticos de los métodos de enseñanza. En este periodo, las Normales transformaron su quehacer formativo y pasaron de enfatizar en la dimensión metodológica de la pedagogía a un enfoque centrado en los conceptos y la práctica de la pedagogía activa y del conocimiento experimental.

La educación a nivel de la nación ha sufrido múltiples cambios, apoyados en las Normales Rurales, que tenían la misión de formar a los nuevos maestros que reforzarían la enseñanza en las zonas rurales, apartadas de los centros urbanos, y, con ello, disminuir los niveles de analfabetismo que se presentan en el país.

Las Escuelas Normales Rurales se crearon por la Ley 12, del 17 de diciembre de 1934; tenían como finalidad específica preparar a las maestras para la educación primaria rural; Julio Sieber, citado por Helg (1987), indica que:

... estas instituciones estaban abiertas a las jóvenes que hubieran terminado la primaria, y prepararían en dos años de internado las docentes rurales. La formación incluía, de una parte, los conocimientos elementales, y, de otra, trabajos manuales y agrícolas e higiene (8).

Las Escuelas Normales Rurales para mujeres se crearon por la Ley 12, del 17 de diciembre de 1934; se constituyeron en uno de los instrumentos privilegiados por los gobiernos liberales para implantar sus políticas de modernización, democratización y asistencia social, hacia la población campesina; estas instituciones se abrían a las jóvenes que hubieran terminado 
la primaria y prepararían en dos años de internado a las docentes rurales. La formación incluía, según Triana (2010), de una parte, los conocimientos elementales, y, de otra, trabajos manuales y agrícolas e higiene (204).

Las Escuelas Normales Agrícolas se originaron en la necesidad de formar maestros para la educación vocacional agrícola. El Decreto 489, de 1949, estableció el Plan de estudios para las Escuelas Normales Agrícolas, que abarcó, según el Ministerio de Educación Nacional (1949), actividades prácticas agropecuarias, técnicas, pedagógicas y de cultura general.

Mediante las reformas de la educación normalista se definió como tiempo de estudio para estas instituciones un periodo de seis años, que incluyen un año de práctica y un nuevo Plan de estudios, mediante Resolución 4785 de 1974, reglamentaria del Decreto 080 del mismo año. El proceso de la diversificación educativa se consolidó en 1978 con la expedición del Decreto 1419, en que se establece el cambio oficial de las Escuelas Normales, en cuanto a su función de formar maestros, para formar bachilleres pedagógicos.

El Decreto 1348 de 1990 manifestó que el país requería de un maestro nuevo, con formación integral, investigador y animador de acciones de desarrollo comunitario; estableció ocho años de formación en una Escuela Normal, título de maestro, con una opción de énfasis y dedicación exclusiva de las Escuelas Normales a la formación de maestros.

A finales de los años 90, surge una nueva normatividad, que reestructuró a las Escuelas Normales y les exigió Acreditación previa para continuar funcionando. Por lo tanto, se puede afirmar que la Escuela Normal Superior tiende a desaparecer, razón por la cual es necesario reactivar su función en el campo educativo, lo cual se puede lograr si se potencia la práctica pedagógica para lograr maestros normalistas competentes frente a los Licenciados y demás profesionales que actualmente se están desempeñando en el ámbito educativo.

En el gobierno de Ernesto Samper Pizano, el 19 de diciembre de 1997 se emitió el Decreto 3012, en el cual se adoptaron las disposiciones para la organización y el funcionamiento de las Escuelas Normales y se obligó a las instituciones a continuar otorgando el título de maestros normalistas superiores. Aquellas Normales interesadas en otorgar el título de maestros normalistas superiores debían asumir el proceso de Acreditación previa que garantizaba condiciones de excelencia en la formación de maestros para los niveles de preescolar y educación básica primaria. 
A partir de 2008, con la expedición del Decreto 4790, se establecen las condiciones básicas de calidad del programa de formación complementaria de educadores en las Escuelas Normales Superiores, en el nivel de preescolar y de básica primaria, que estipula que respondería al PEI, al tomar en cuenta los principios pedagógicos de educabilidad, enseñabilidad, pedagogía y contextos. Se destacan como condiciones de calidad: las prácticas docentes en la formación complementaria, el Plan de estudios y práctica pedagógica investigativa relacionada con los temas de preescolar y básica primaria, las innovaciones en el campo educativo que fomenten la investigación y la estructuración de los Planes de estudio en créditos académicos.

Así, las Escuelas Normales Superiores se constituyen en instituciones destacadas por ser instituciones formadoras de maestros para la educación preescolar y básica primaria, dos niveles educativos claves en tanto en ellos se cimientan las bases para los futuros aprendizajes y para la vida, con valoración de la fundamentación del Decreto 4790, que reorganiza y le da sentido al trabajo del maestro en formación para asumir sus compromisos, que lo conduzcan por el sendero de la responsabilidad y el desempeño.

Las Escuelas Normales Superiores centran su gestión en atender la formación inicial de educadores para el ejercicio de la docencia en el nivel de preescolar y en el ciclo de educación básica primaria. En Colombia, a partir de la Ley General de Educación de 1994 y el Decreto 3012 de 1997, las Escuelas Normales Superiores asumen, además, la posibilidad de formación para el nivel preescolar. ${ }^{3}$

3 Artículo 4 del Decreto 3012 de 1997.- Los programas de formación de educadores que ofrezcan las escuelas normales superiores se estructurarán teniendo en cuenta, en especial, el desarrollo armónico de los siguientes núcleos del saber: a. La educabilidad del ser humano, atendiendo su proceso de desarrollo personal y cultural y sus posibilidades de formación y aprendizaje; $b$. La enseñabilidad de las disciplinas y saberes producidos por la humanidad, en el marco de sus dimensiones histórica, epistemológica, social y cultural, correlacionando el contexto cognitivo, valorativo y social de quien aprende $\mathrm{y}$ sus posibilidades de transformación en contenido y estrategias formativas; c. El currículo, la didáctica, la evaluación, el uso pedagógico de los medios interactivos de comunicación e información y el dominio de una segunda lengua; d. La estructura histórica y epistemológica de la pedagogía, su interdisciplinariedad y sus posibilidades de construcción y validación de teorías y modelos; e. Las realidades y tendencias sociales y educativas, de carácter institucional, regional, nacional e internacional; $\mathrm{f}$. La dimensión ética, cultural y política de la profesión educativa y las consecuencias formativas de la relación pedagógica 
En el programa de formación complementaria, los jóvenes buscan el camino de la docencia por una u otra razón; no es fácil ser maestro, pues es una carrera que requiere de responsabilidad, compromiso, amor, creatividad, innovación, flexibilidad, paciencia, entre otras, para que el desempeño sea el mejor y se logre formar seres humanos integrales, que sean capaces de desenvolverse en la sociedad.

Los planteamientos presentes en la Constitución Política de 1991, en la Ley 115 de 1994, y en la mayoría de los estudios teóricos y proyectos de reforma, no dudan en vincular la transformación de las instituciones y el incremento de la calidad educativa con la modificación de la práctica pedagógica de los maestros y el enriquecimiento de su desarrollo profesional, para lo cual han de comprometerse las instituciones formadoras de maestros como parte constitutiva del Sistema nacional de formación de educadores.

La formación de maestros, en toda su complejidad, requiere que las Escuelas Normales Superiores se comprometan con la fundamentación pedagógica de una propuesta de formación inicial de maestros para el nivel de preescolar y el ciclo de la básica primaria, formulada a partir de los núcleos del saber pedagógico, enriquecida con la investigación educativa y viable a través de la gestión institucional en su dimensión formativa y en su relación con el contexto.

La Escuela Normal Superior recién comienza a romper con el viejo esquema de la práctica docente como repetición, que recibía de manera desordenada y fragmentada las producciones de las ciencias, situación generada por la falta de un saber con el cual sustentar o debatir las relaciones de ellas con la enseñanza, el aprendizaje y la formación. Esta ruptura suscita espacios de reflexión y de investigación que llevan a que toda la institución fuera un lugar para conjugar el saber pedagógico, los saberes disciplinares y las propuestas didácticas.

El maestro, como intelectual de la pedagogía, participa en la construcción de conocimiento a partir de dos acciones fundamentales: una, comprometida con la elaboración del saber pedagógico fruto de la reflexión constante sobre su práctica cotidiana y su contrastación con el conocimiento pedagógico y didáctico acumulado para resignificar dicha práctica y construir saber pedagógico profesional propio; la otra, comprometida con 
la construcción de la fundamentación pedagógica del $\mathrm{PEI}^{4}$ y de su propuesta de formación de maestros en interacción interdisciplinaria.

Los retos que actualmente tienen las escuelas normales en la formación de los maestros y maestras que requiere el país, se dirigen al desarrollo de una ciudadanía participativa, solidaria y tolerante, reconocedora del papel e importancia de la educación para los procesos de desarrollo; esto implica seguir interrogándonos, repensar seriamente la formación de los maestros que actualmente se desempeñan como formadores de formadores para comprometernos con la transformación y el mejoramiento.

\subsection{Papel desarrollado por las Escuelas Normales a través de la Historia}

Las Escuelas Normales Superiores han tenido grandes cambios en todo su proceso histórico y sus internados surgieron como molde para cultivar la vocación del maestro como un ser religioso, muy comprometido con su noble oficio, que implica votos de entrega y servicio, con sus salarios mínimos, que no alcanzaban para solventar sus necesidades básicas y solo buscaban defender su papel como educadores comprometidos en su labor.

El objetivo de las Escuelas Normales creadas desde el siglo XIX en el país era formar maestros prácticos más que pedagogos eruditos (Decreto 491 de 1904, Título XII) que tuvieran la capacidad de responder a una instrucción primaria, donde se enseñaran las nociones elementales y prepararan a los jóvenes para el trabajo, con un criterio de actitudes morales y éticas.

La formación del maestro gozó de mucho reconocimiento, por ser una persona comprometida con la producción teórica y educativa, lo que comprometía a las Escuelas Normales en la formación pedagógica, con el niño como el centro del proceso educativo y el maestro como guía y orientador para crear las condiciones en la construcción del nuevo ciudadano.

Con la promulgación de la Ley General de Educación, Ley 115 de 1994, que significó, en particular, una reforma importante en las Escuelas Normales, se señalan las normas generales para regular el Servicio público de la educación, que cumple una función social acorde con las necesidades e intereses de las personas, de la familia y de la sociedad. En el Artículo 112 de la Ley General de Educación, sobre las instituciones formadoras de educadores, se establece que:

${ }_{4}$ PEI: Proyecto Educativo Institucional. 
...las Escuelas Normales debidamente reestructuradas y aprobadas, están autorizadas para formar educadores en el nivel de preescolar y en el ciclo de educación básica. Estas operarán como unidades de apoyo académico para la formación inicial de docentes $\mathrm{y}$, mediante convenio celebrado con instituciones de educación superior, podrán ofrecer formación complementaria que conduzca al otorgamiento del título de normalista superior (Ley 115 de 1994).

La evolución de las Escuelas Normales se centraba en la formación académica de los maestros a través de conocimientos profundos de los fundamentos pedagógicos y científicos, que contribuyen a fortalecer y entender la importancia de las Escuelas Normales que, desde 1821, han venido cumpliendo un gran papel y poco a poco se han venido transformando y actualizando debido a las exigencias de la época; fueron las pioneras en la formación de docentes que se encargarían de instruir a los niños tanto del sector urbano como del rural; las primeras en implementar metodologías como la de Pestalozzi y Lancaster y las que, en la actualidad, se ven amenazadas ante las decisiones de políticas públicas educativas que determinarán su continuidad, atendiendo a exigencias de índole mundial.

También, decretó la Acreditación de los programas de las Escuelas Normales Superiores con el fin de promover el mejoramiento continuo de su calidad, fomentar los procesos de autoevaluación institucional y favorecer el sentido y la práctica de la investigación pedagógica.

El compromiso es la reestructuración de las Normales, porque el reto del siglo XX nos los impone, pero sabemos también que las Normales tienen una gran misión, que es la de formar maestros para una nueva sociedad, especialmente en relación con los niños y los jóvenes y, cuando nos referimos a ellos, no creemos que por eso es más fácil la formación del normalista; es exactamente todo lo contrario.

El programa de formación complementaria busca que los docentes diseñen y apliquen estrategias pedagógicas innovadoras que incidan en el desarrollo de las competencias y en el mejoramiento de la calidad de la educación. El desarrollo profesional de los docentes y directivos del país apunta a formar un educador de la más alta calidad científica y ética; a desarrollar la teoría y la práctica pedagógica como parte fundamental del saber del educador; a fortalecer la investigación en el campo pedagógico y en el saber específico; y a preparar educadores para los diferentes niveles y formas de prestación del servicio educativo. 
Esto implica desarrollar acciones y estrategias, tanto en la formación permanente o en el servicio de los docentes, orientadas a la actualización profesional y al perfeccionamiento de la enseñanza, como en la formación inicial ofrecida por las Facultades de Educación y las Escuelas Normales Superiores. La formación inicial del docente se convierte en la base y pilar del Sistema educativo en la medida que prepara a los profesionales para el ejercicio de la docencia y el fortalecimiento y cualificación de estos programas, lo que permitirá tener docentes altamente preparados para asumir los retos y compromisos que requiere el desarrollo social y local.

En esta línea, las Escuelas Normales Superiores se constituyen en un foco importante de atención por ser instituciones educativas formadoras de maestros para la educación preescolar y básica primaria y por el rol protagónico que, a nivel regional y nacional, han tenido en la Historia de la Educación del país.

El papel de las Escuelas Normales Superiores es importante y goza de gran reconocimiento por parte de otros establecimientos, que las toman como referente y modelo en sus procesos, no solo para la formación de los docentes, sino también como institución educativa en sí misma, razón por la cual se torna importante acompañarlas, al fortalecerlas y consolidarlas como ejemplos para la región y el país.

El trabajo pedagógico realizado por las Normales se revela donde el maestro tiene, por lo tanto, que aprender de la teoría de la ciencia de enseñar. La práctica sin la teoría es mera rutina. Según Álvarez (1995), la enseñanza pedagógica tiene que ser teórica y práctica. (67)

En Colombia, se puede decir que, a pesar de las tensiones presentadas, aún conservan su esencia y mantienen el objetivo de formar a los docentes para la educación básica primaria, con la convicción de ofrecer mejores oportunidades para los niños y jóvenes. No obstante, cabe señalar que algunas Leyes, Decretos y Resoluciones han terminado por ser guía para reformas pertinentes en las Escuelas Normales.

Es importante tener en cuenta que la vida de la escuela supone discernimiento, reflexión y toma de decisiones para los estudiantes, donde la pedagogía, los valores y criterios relacionados con la formación de maestros superiores se anclan a los contextos escolares específicos en el trajinar del día a día, donde el trabajo implica relaciones con seres humanos, que se manifiesta en una dimensión ética basada en los actos sociales cotidianos.

La pedagogía, como saber fundante que las Escuelas Normales vienen estructurando, se enfoca en el maestro como acompañante, como orientador, 
como un amigo, que apoya pero exige; como un par que se convierte en ese faro que ilumina, que abre las puertas al saber, que resplandece, que muestra todo un espectro de posibilidades y caminos, que enseña a crecer, autovalorarse y a aumentar su autoestima; que, en la interacción, enseña y aprende como un verdadero guía que trabaja con pasión, que sensibiliza a sus estudiantes para que entiendan que la valoración prima sobre la calificación, que la formación supera la simple información, y los motiva a alcanzar la felicidad antes que el éxito.

Para que un maestro se convierta en un verdadero guía, debe ser un maestro coherente con los ejes misionales de la institución y conocedor del horizonte institucional. Su función es convertirse en pedagogo e investigador; capaz de aplicar didácticas y metodologías avanzadas; que contextualiza y conoce los principios rectores de una educación pertinente.

Al referirse a la Historia de las Escuelas Normales se necesita retomar el testimonio de la maestra rural (1949).

Figura 1. Lucrecia Muñoz Palacios.

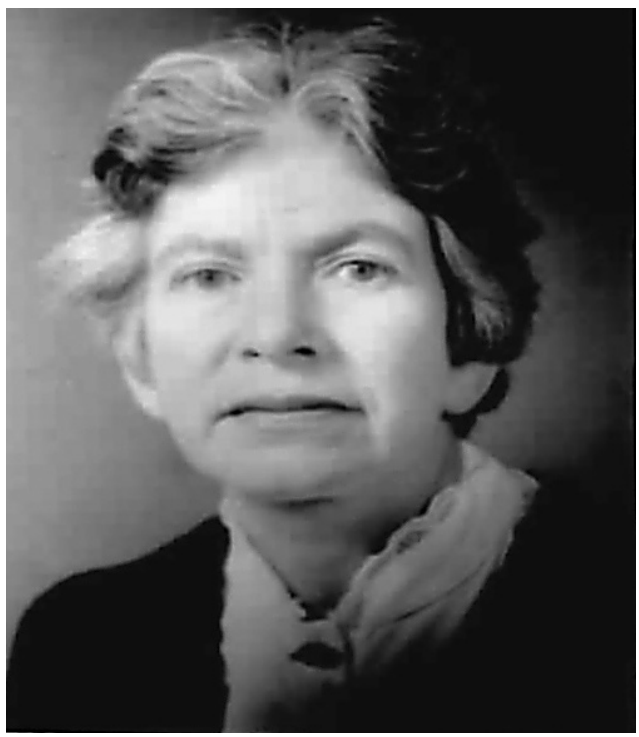

Fuente. Lucrecia Muñoz Palacios $1990^{5}$

5 Nacida en el municipio de La Cruz (Nariño), el 8 de julio de 1933. Sus padres fueron: Antonio Muñoz Ordóñez y Aurelia Palacios Buendía; sus hermanos: María Jesús, Nidia, Antonio, Leopoldo, Ana Rita, Aurelia, Ester, Rosario, Hernán y Jesús. Casada con Naún Cabrera Ordóñez; sus hijos: Edgardo, Claudia, Mercedes, Fernando. 
Las maestras se formaban con tres años de estudio; el título era maestra de escuela rural. La Institución: Escuela Normal Rural del Mayo, graduada el 22 de julio de 1949; estábamos capacitadas para trabajar solo en el campo; para los pueblos, eran otros maestros, con una preparación más profunda en cuanto a pedagogía; sobre todo, eran maestros en ese tiempo, porque la mujer estaba dedicada a las labores del hogar y el hombre tenía que sostener la casa.

Después, la formación de maestras de tres años pasó a cuatro años; la preparación seguía siendo la misma; lo que la hacía diferente era la disciplina, el respeto por los mayores, el respeto por las autoridades; de igual manera, se tenía respeto por los alumnos; sin embargo, cuando había una falta grave, lo castigaban con regla o lo sacaban de la clase y se llamaba al padre de familia para dar la queja y hacer los correctivos pertinentes.

Mi formación inicial la realicé en la escuela primaria; quien la dirigía eran las Hermanas Vicentinas, con un uniforme muy especial y llamativo, que merecían mucho respeto; además, la formación era muy rigurosa y ordenada: se trabajaba en la mañana y en la tarde, logrando una integralidad en el conocimiento de las materias, donde se aprendía de memoria los contenidos.

Una vez graduadas como maestras, había que hacer solicitud al secretario de Educación del Departamento y le hacían el nombramiento; siempre tocaba de buscar un apoyo político para que realicen el nombramiento en La Cruz; me nombraron como maestra en Juan López, luego estuve en Briceño, San Bernardo y San José; en ese tiempo estaba como secretario de Educación el Doctor Alfonso Rebolledo Pérez, quien me ayudó para trabajar en el campo; empecé a laborar de quince años (1949). Después me fui a estudiar a Bogotá con una beca y logré quedarme dos años interna aprendiendo un poco de pedagogía, didáctica y fundamentos $\mathrm{y}$, cuando regresé, me nombraron como profesora de la escuela anexa y después fui profesora de la Normal, hasta que me jubilé.

La disciplina en la Normal era bien estricta, toda pequeña falta la castigaban de una manera o de otra y, en casos, pasada de tono; a veces, muchos niños informaban a sus padres $y$, si el castigo era muy duro, preguntaban qué falta cometió en la escuela y en la casa se aplicaba con correa. La urbanidad era una clase aparte, como decir matemáticas, castellano, sociales; habían textos que los maestros conseguían; entonces, nos iban dando lecciones de acuerdo al avance del contenido del texto; era muy estricto; en las izadas de bandera, una formación rigurosa; el saludo a la bandera era como soldados, 
con todo el respeto posible; en las casas, donde estaba izada la bandera, la gente que pasaba se hacía el saludo y se quitaban el sombrero; muchas cosas cambiaron para bien; no estoy de acuerdo que se critique a la gente joven porque es alegre, cuando está en el colegio tiene novia; las travesuras de la juventud son acciones propias de la adolescencia.

Los materiales que se utilizaban en la primaria o secundaria: en el aula de clase existía un tablero de madera con patas, que se podía mover, y se buscaba la tiza para poder escribir; después de eso ya fue la pared, donde había un tablero grande; los alumnos ya usaban pizarra: era un rectángulo pequeño con una lámina negra, que era de piedra; por un lado era lisa y por el otro tenía líneas para escribir derecho y el lápiz era de unos veinte centímetros y era de piedra y era tisudito ${ }^{6}$ que escribía; había cuadernos marca Norma, era con renglones trazados y los cuadernos de dibujo eran de forma horizontal y allí hacíamos los dibujos y había profesor para dibujo y para pintar; las lecciones que escribían era para aprenderlas de memoria y, si no dábamos las lecciones como eran, nos bajaban las notas; los libros con que enseñábamos a leer se llamaban Alegría de Leer y había de primero a cuarto; el método que se utilizaba era método de palabras normales y venían las palabras muy familiares, como se escribe mamá, papá, casa, y eran las primeras palabras que nos enseñaban a leer y los niños que pasaban de primaria a secundaria donaban los libros para la biblioteca y servían para que los niños pudieran aprender a leer, siendo útiles para muchos niños.

Las Normales formaban para maestras rurales y solo se formaban mujeres y, en el grupo donde yo estaba, habíamos siete mujeres, donde se formaban muy bien en pedagogía y fundamentos; como compañeras tenía a: Laura Cerón, Emérita Muñoz, Carmen Muñoz, Rosario Guerrero, Lola Díaz, Emérita Enríquez y Rosario Meneses.

Las materias que daban eran matemáticas, castellano, estudios sociales, cívica, sobre gobierno, deberes, derechos, ciencias naturales, botánica, trabajos manuales, modistería, costura; al finalizar el año había exposición de todos los trabajos manuales que se elaboraban durante todo el año; se hacía la práctica en la Anexa y las primarias del pueblo, solicitando permiso a los directivos de cada escuela para realizar la práctica.

La primera rectora de la Normal fue la señorita Nohemí Salcedo, oriunda de La Unión (Nariño); luego vienen Gonzalo Bravo y Pastor

${ }_{6}$ Tisudito, que escribía muy bien y con buena tinta. 
Bolaños, y la directora de la Anexa era la señorita Ernestina Bolaños y, luego, Alberto Palacios, muy preparado, dedicado y trabajaba como maestro en pedagógicas y hacia una labor social.

El papel de las Normales era educar y preparar para ser maestros rurales, donde se daban fundamentos, la práctica pedagógica; además, sacábamos a los niños a las casas y a los campos a desyerbar, a realizar charlas en los hogares, aseo de andenes; la salida a la iglesia, era rezar harto en las tardes y los domingos se llevaba a todos los niños a la misa.

La preparación del maestro era rigurosa en cuanto al cumplimiento, la manera como debía comportarse el maestro con la sociedad y con los niños; la urbanidad para que aprendan a ser buenos ciudadanos, competentes para el trabajo.

La educación ha ido cambiando de manera muy fuerte $\mathrm{y}$ se hace buena labor social; como maestra, me siento realizada y ejercí más de treinta años de experiencia, cumpliendo con el deber, y el trabajo se siente realizado; el legado dejado: el cumplimiento, la disciplina, el respeto; ya, como personas que salían a trabajar, tenían que respetar, amar y querer a su Normal y a sus maestros, a manifestarse como personas preparadas, a tener buenas amistades, practicar buenas costumbres, el respeto, y que tenían que continuar estudiando.

La escuela tradicional formó niños de bien; los alumnos eran más obedientes, más cercanos, se hacían respetar, era buena; había una escuela para hombres y otra para mujeres, pero no se queda atrás la educación de ahora: es una formación más amplia, más medios para aprender y se busca despertar la responsabilidad a una enseñanza más integral y transversal.

La profesión como maestra me trae satisfacción, me siento realizada porque fui escalando en la preparación para conquistar nuevos contextos; mi primer sueldo fue de 70.000 y se fue incrementando 75.000 y 80.000 pesos, los cuales alcanzaban para los gastos del hogar; además, el valor de las cosas era relativo, donde se compraba lo necesario y alcanzaba para ahorrar.

Los estudiantes de este tiempo ya utilizan el computador para realizar las tareas y aprender muchas cosas más; la educación de hoy debe estar enfocada en cosas grandes, donde el maestro busque prepararse más, expandirse en la sociedad, siendo, por ejemplo, las normas de urbanidad y el apoyo constante del padre de familia.

Las Normales cumplen doscientos años de creación y han desarrollado un trabajo en favor de los alumnos de acuerdo a las facilidades, a la revisión 
constante de las autoridades educativas, el presupuesto que manejan para darle las comodidades en las escuelas, en pupitres, sillas, materiales didácticos; las Normales le han aportado desarrollo al país y un cambio muy productivo en la educación, buscando acabar con el analfabetismo que existía en Colombia.

Las actividades tenían que cambiar con tantas necesidades de conocimientos, para realizarse como personas y profesionales de bien; los currículos y desempeños han mejorado para bien, pero faltan algunas cosas para destacarse en el trabajo, para superarse y ser cada día mejores.

El maestro de este siglo debe amar la profesión que ejerce y estar comprometido con su desempeño:

"El amor todo lo puede, amar a los niños, amar las cosas que hacen cada día superándose, vivir y emplear el producto de su trabajo en buenas cosas, como se ve reflejado en cómo lo hacen y comparten, viven decentemente con ilusiones y ganas de enseñar, hay cambios de vida para bien del núcleo familiar.

El maestro busca la integralidad para formar con principios y valores."

Figura 2. Diploma Escuela Normal Rural Del Mayo.

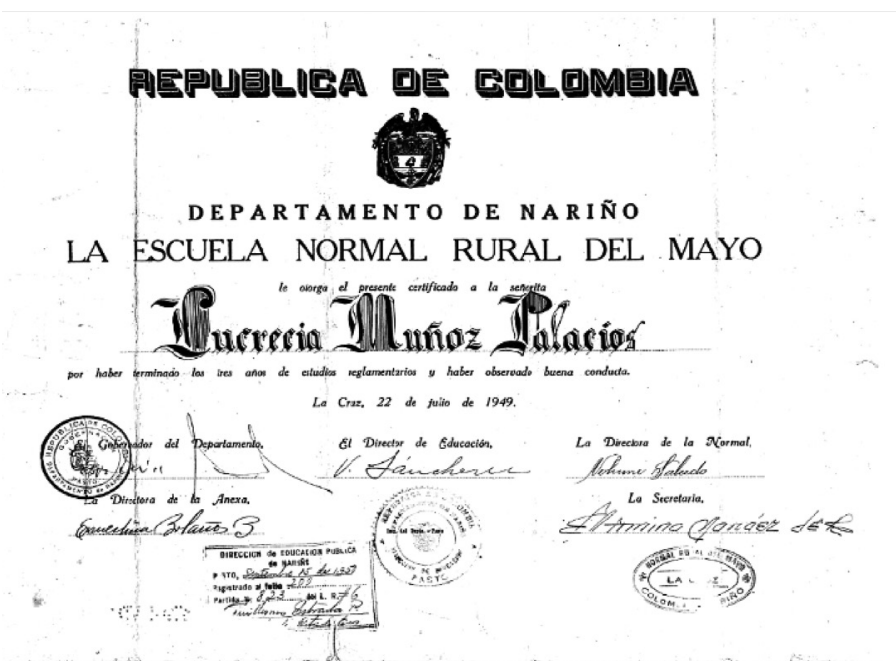

Fuente: Lucrecia Muñoz Palacios. 1949-1951. 
Figura 3. Diploma de Maestra de Escuela Rural

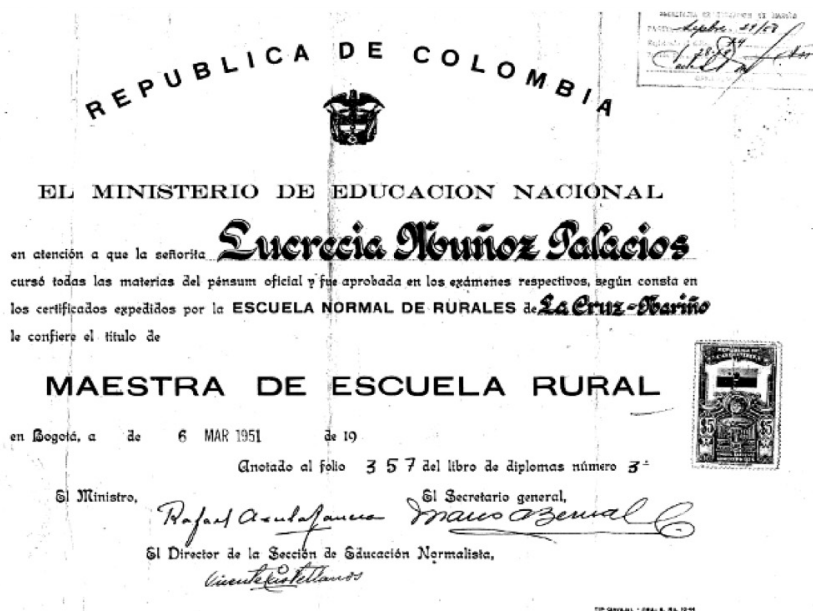

Fuente: Lucrecia Muñoz Palacios. 1949-1951.

\subsection{El maestro y la práctica pedagógica en los procesos de formación}

Sin duda, formar a un maestro no es algo reciente; a partir de la última década del siglo pasado, en un documento de la Unesco conocido como el Informe Delors (Delors, 1996, 157) se sostiene que para que la educación enfrentase los cambios que la dinámica social global exige, es necesario contar con maestros que asuman el reto de la formación para la integración, la crítica, la autonomía y la tolerancia, pues se requiere transmitir, masiva y eficazmente, un volumen cada vez mayor de conocimientos teóricos y técnicos evolutivos, adaptados a la civilización cognitiva cambiante. También, el documento atribuye a los maestros la responsabilidad de enfrentar el reto de favorecer en los estudiantes y en sí mismos la adquisición de habilidades, competencias y destrezas que les permitan aprender a aprender, a ser, a hacer y a convivir.

Desde esta perspectiva, los maestros no solo tendrán que enfrentar los retos que la transformación social conlleva, sino, además, enfrentar cambios estructurales con respecto a la profesión. El informe referido parte de la premisa de que para mejorar el desempeño profesional del maestro es necesario empezar por mejorar sus condiciones académico-pedagógicas, salariales, de formación, actualización, capacitación e infraestructura. El docente, señala el texto, "no 
podría responder a lo que de él se espera si no posee los conocimientos y la competencia, las cualidades personales, las posibilidades profesionales y la motivación que se requiere" (Delors, 1996, 158).

Según Torres (1997), el antiguo modelo promueve conocimientos, habilidades, valores, actitudes y visiones de la enseñanza y el aprendizaje anquilosados, funcionales para el viejo modelo educativo y el viejo papel docente que se pretende superar: el educador entrenado en la obediencia y en la sumisión antes que en el desarrollo de la creatividad y de la autonomía; preparado para implementar, no necesariamente para comprender lo que hace, por qué lo hace y el contexto en el cual trabaja; equipado para la reproducción de un modelo de enseñanza y aprendizaje bancario, memorístico, pasivo y enciclopédico (14-15).

Ahora, el propósito es ofrecer una formación que articule con mayor armonía al proceso seguido en la Escuela Normal y el que sigue la educación básica; entonces, el desarrollo de competencias, habilidades, destrezas y conocimientos tendrá que convertirse en insumo básico para el análisis, la reflexión y la transformación de la formación profesional y de la práctica docente.

La formación es algo que se adquiere durante la estancia en la Escuela Normal, donde se aprende a ser maestro. La formación se considera como un momento en la vida del sujeto, que transcurre en un tiempo y espacio determinados; por ello, la mayoría de los profesores se refieren a la formación como algo pretérito. Esta concepción es la más arraigada entrelos profesores y las autoridades educativas y se manifiesta en la irrisoria cantidad de oportunidades de participación en estudios posteriores a la Normal y en la casi nula demanda de los profesores en servicio para que estos cursos se incrementen.

Según Ferry (1990), la formación no debe reducirse a una acción ejercida por un formador sobre un "formado" maleable que reciba de forma pasiva la configuración que le imponga el formador. El proyecto insensato de moldear al otro, de crear un ser a su imagen, de infundirle vida, que es el fantasma del animador, lo único que puede hacer es infringirle la muerte (53).

La formación tiende a verse en un sentido mucho más amplio y, por lo tanto, difícilmente quedaría reducida a la instrucción recibida en la Normal o la experiencia adquirida y acumulada en las escuelas de práctica. Esto lo reconocen los maestros normalistas; en sus discursos sostienen que los futuros profesores hoy son "docentes en formación". Este cambio de denominación, donde dejan de considerarlos estudiantes, ha llevado a los maestros a tratarlos de otra manera. 
La formación tiende a verse en un sentido mucho más amplio y, por lo tanto, difícilmente quedaría reducida a la instrucción recibida en la Normal o la experiencia adquirida y acumulada en las escuelas de práctica.

La formación del maestro a través de la práctica se ha vinculado a las preguntas: ¿qué debe saber un maestro de primaria?, y ¿a través de qué medios es necesario formarlo? Ambas preguntas se anclan a la "misión del maestro de preescolar y primaria" y se indagan mediante los análisis de los archivos históricos, lo dicho y lo no dicho, y se visibiliza en el estudio de las diferentes formaciones discursivas realizado a la práctica en la Escuela Normal. Esta indagación patentiza unas formas de saber y poder que circulan en la práctica pedagógica de los normalistas, desde el método de la observación, experimentación y cuantificación, tales como:

-Formar en buenas costumbres, como pautas de comportamiento social y disciplinar, mediante una práctica que demuestre la formación de hábitos considerados socialmente correctos y la represión de los malos de tal manera que se creen en los niños hábitos virtuosos, modales propios de las personas bien educadas. Se visibiliza una ética que insinúa, a través de sus gestos, la moral cristiana, mediante un código de prohibiciones y privaciones, que en la práctica de formación prescribe, encamina o enjuicia y donde el aprendiz reproduce al tomar el ejemplo de su maestro de práctica.

Este gesto pedagógico y formativo supone preguntar: ¿dónde se plantea una ética para el cuidado de sí mismo?, ¿cuáles son las prácticas o tecnologías para que los niños construyan y perfeccionen su sismicidad?: es decir, qué acciones puede orientar el maestro en formación para que él, según Foucault, en Martín y otros (1993),

con su propia fuerza o con la ayuda de otros, pueda efectuar una serie de operaciones sobre su cuerpo, su alma, su pensamiento, su comportamiento o su modo de existencia con el propósito de ir transformándose y reconstruyendo su identidad de tal modo que consiga cierto estado de felicidad, de pureza de sabiduría, de perfección o inmortalidad (26).

Para el normalista en su práctica, la orientación teórica se precedía de que el niño bien educado era el instruido y el culto; según Rousseau, el niño bien educado era el que estaba bien desarrollado; en su obra: $E l$ Emilio, presenta el ideal de hombre racional hacia el cual debe tender la 
educación: el hombre de naturaleza, que supone una formación centrada exclusivamente en lo constituido de la naturaleza humana. No se educa para una profesión u oficio determinado, sino para ser hombre. Esta ilustración muestra que en la formación de los normalistas tuvieron más influencia las concepciones pedagógicas de Pestalozzi y Herbart y demás antecesores de Rousseau.

Las Escuelas Normales se han caracterizado por la fortaleza para formar verdaderos maestros especialistas en la enseñanza, a través de la práctica pedagógica articulada a su erudición teórica y al saber pedagógico; antes y durante los años 1960 a 1980, la preocupación residía con mayor énfasis desde el método y, a partir de las décadas 1990 y 2000, la preocupación se centra en el dominio de los contenidos que se van a enseñar y la ciencia de cómo enseñarlos y la decisión de qué, cómo, cuánto y cuándo enseñarlo

La inserción del normalista en el mundo escolar y sus fuertes vínculos con el trabajo comunitario ha permitido configurar un sujeto social y trabajador de la cultura que, en su trayecto de formación, va asumiendo la pedagogía como puente de encuentro entre el hombre, su lenguaje, el conocimiento y las interioridades de la cultura con que se relaciona.

\subsection{Logros conseguidos con las acreditaciones por parte del MEN}

La acreditación es un proceso de estudio y evaluación de las Escuelas Normales por el cual las instituciones comprueban la calidad de sus programas y la suya propia ante sí misma. Acreditar se refiere a afamar, dar crédito o reputación.

El Decreto 3012 de 1997 (derogado) establecía la organización de las Escuelas Normales superiores y explicitaba los requisitos y el procedimiento para la Acreditación previa, según lo estableció también la Ley 115 de 1994 para "mantener un mejoramiento continuo de la calidad de los docentes", se delimitó el campo de desempeño docente de los egresados y normalistas superiores, al servicio educativo en nivel de preescolar y en el ciclo de educación básica primaria.

La Acreditación previa (1998-1999), en cumplimiento de los ordenamientos legales señalados por la Ley 115 de 1994 y, en especial, por el Decreto 3012 de 1997, se adelantó entre los años 1997 y 1998.

La Acreditación de calidad y desarrollo (2002), consistente en la determinación del cumplimiento de los requisitos de calidad de los 
programas ofrecidos y de desarrollo de los fines propios de la educación, se otorgaría por un período de 5 años.

Así, en el año 2001, mediante el Decreto 642 (derogado), se establecía que al ciclo complementario también podían ingresar las personas que acreditasen título de bachiller, quienes cursaban seis (6) semestres, en lugar de cuatro.

En el año 2002, quedaron para el país un total de 137 Escuelas Normales Superiores establecidas y acreditadas: 129 estatales y 8 privadas.

En este marco, y a puertas de finalizar el término de la Acreditación de calidad y desarrollo, (en 2007), se promulgó el Decreto 1075 de 2015, por el cual se establecieron las condiciones básicas de calidad del programa de formación complementaria de las Escuelas Normales Superiores (en adelante ENS) y se dictaron otras disposiciones, que implicaron nuevos ajustes en la dinámica de la ENS.

En La Acreditación de verificación de las condiciones de calidad (2010-2012), mediante Resolución 505 de 2010, se requirió el informe ejecutivo del PEI, que incorpore el currículo y Plan de estudios previsto para el programa de formación complementaria, la autoevaluación del programa de formación complementaria y su plan de mejoramiento.

Respecto a la Acreditación de alta calidad (2018-2019), conlleva observar que las fortalezas de las ENS son diversas, acorde con cada contexto, que desataca que son proveedoras de docentes en el sector rural, donde los normalistas trabajan en básica primaria y educación preescolar, realizan actividades de carácter creativo e innovador en la didáctica y enseñanza de matemáticas, inglés, ciencias sociales, ciencias naturales, lengua castellana, entre otras áreas del conocimiento.

En el Decreto 4790, de diciembre de 2008 (MEN), sobre las Condiciones básicas de calidad, el programa de formación complementaria de la ENS deberá cumplir estas condiciones básicas de calidad:

1. Pertinencia del PFC

2. Propuesta curricular y plan de estudios

3. Innovaciones en el campo educativo

4. Proyección social.

5. Personal docente y directivo

6. Medios educativos y mediaciones pedagógicas

7. Infraestructura y dotación

8. Autoevaluación institucional coherente con el PMI. 
9. Plan de seguimiento a egresados.

10. Prácticas docente

11. Temas de enseñanza obligatoria en la educación preescolar y básica primaria.

12. Modalidades de atención educativa a poblaciones

13. Estructura administrativa y recursos financieros.

El Decreto 1236, del 14 de septiembre de 2020 (MEN) adicionó el Capítulo 7 al Título 3 Parte 3 Libro 2 del Decreto 1075 de 2015, único reglamentario del sector Educación, y se reglamenta la organización y el funcionamiento de las ENS como instituciones educativas formadoras de docentes.

Las ENS son instituciones educativas que prestan el servicio educativo en los niveles de preescolar, básica y media y que las autorizan para ser formadoras de docentes de educación inicial, preescolar y básica primaria o como directivo docente - director rural, mediante el programa de formación complementaria.

Las ENS deben atender los procesos de: Formación, investigación, evaluación y extensión. Los principios de educabilidad, enseñabilidad, pedagogía y contextos e interculturalidad, durante todo el proceso formativo, y formación de futuros docentes a través de procesos educativos que atiendan los requerimientos sociales, culturales y poblaciones de las distintas regiones del país.

\subsection{Papel de los maestros superiores egresados de las ENS de Colombia}

Ser maestro normalista superior implica asumir una postura centrada en el humanismo, desde una ética y vocación profesional de la educación, que debe asumir procesos que conduzcan a encontrar nuevos significados a su tarea en la cotidianidad escolar y social, para no solo ser portador del conocimiento científico, sino generador de movilidad pedagógica, con asunción del rol de investigador, para así legitimarse como maestro de los niveles de preescolar y básica primaria.

Como docentes de ENS y, más concretamente, del Programa de formación complementaria, y en el marco de la actividad pedagógica, consideramos de interés y utilidad ser coherentes con la responsabilidad de formar maestros, para lo cual se cree conveniente indagar en el tema de la investigación formativa. 
Las instituciones formadoras de maestros, como las ENS, deben garantizar a Colombia un nuevo profesional de la educación, con el dominio de un saber fundante, como lo es la pedagogía; un saber específico; desde una concepción humanística, fortalecido por su praxis pedagógica; es decir, por su capacidad reflexiva, que lleva a que la investigación formativa fuera una herramienta que le permita desarrollar autonomía, autorrealización y lo caracterice por la continua autoformación pedagógica.

La formación en investigación, en el Programa de formación complementaria de las ENS, es posible desarrollarla con diferentes estrategias, como son: el trabajo de grado (con sus diferentes modalidades), el proyecto de aula, el ensayo teórico investigativo, los semilleros de investigación, la implementación de estrategias didácticas para el desarrollo de competencias investigadoras de los maestros en formación, que favorezcan la indagación, desde la concepción de investigación formativa, a fin de fomentar el espíritu científico en los nuevos profesionales de la educación.

La formación del maestro en Colombia está a cargo de la Educación Superior; es decir, desde las Facultades de Educación y desde las ENS, a través de los Programas de formación complementaria principalmente. Por ello, al "normalista superior" se lo reconoce como un egresado de las ENS que, según el decreto 1278 del 2002, lo califica como un profesional de la Educación que se desempeñará como docente en los niveles de preescolar y básica primaria.

La Formación complementaria es otro de los nuevos compromisos que asumen las Normales, donde se prepara un maestro acorde con las necesidades educativas de las comunidades rurales y urbanas. En su práctica cotidiana, el maestro se enfrenta a sus estudiantes y sus expectativas, tan disímiles como el número de aprendices en el aula, y se compromete con las particularidades de cada uno. No solo el saber de cada estudiante es diverso, sino sus modos y fuentes de motivación hacia el aprendizaje.

El lugar que actualmente tiene el maestro le asigna la labor definitiva de formar a las jóvenes generaciones, razón que pone al orden del día la función social de sus acciones. Sabemos que esta responsabilidad social se ha tornado compleja, por cuanto requiere que se apropie de los conocimientos de un campo disciplinar y sea capaz de enfrentarse a los retos que exige una sociedad como la de hoy.

Cuando se piensa que un maestro es un formador de seres humanos y que muchas veces es el profesional que pasa más tiempo con los niños y 
jóvenes, se torna evidente la importancia social de su trabajo y las diversas responsabilidades de su profesión. El maestro contemporáneo se enfrenta a retos que le impone su disciplina y a otros que le demanda la sociedad. Hoy en día, requiere de habilidades diferentes para solucionar con creatividad los primeros, y participar así en la solución de los segundos.

El maestro normalista tiene mucha claridad en cuanto a su formación y desempeño dentro y fuera del aula, es muy consciente de que su trabajo tiene mucha relevancia y expectativas para demostrar qué capacidades teóricas influyen en la orientación de sus niños y cómo su enseñanza es la base para adquirir nuevos conocimientos.

\subsection{Retos para las ENS a partir de la educación virtual en tiempos de adversidad}

Desde las ENS, la formación de niños, desde el preescolar hasta el programa de formación complementaria, ha traído cambios muy profundos e innovadores que llevan a que los maestros asumieran un trabajo disciplinado y ordenado, que se estructura en guías y actividades, donde los niños y jóvenes demuestran sus capacidades para cumplir con este nuevo reto que nos impone una pandemia, que nunca soñamos que se presentaría, pero la estamos enfrentando con fuerza y optimismo, puesto que el maestro lo entrega todo para llegar hasta los sitios más apartados y con ello cumplirle a los niños, padres de familia y la sociedad.

El trabajo desarrollado con los maestros en formación se orienta a revisar planes de área, lineamientos curriculares, derechos básicos de aprendizaje, planes de clase, con lo que se logrará, a través de videos, realizar clases planeadas y estructuradas, que demuestran su creatividad mediante múltiples materiales, para alcanzar resultados que inviten a nuevos cambios y alternativas en este tiempo.

El maestro en formación es consciente de que su responsabilidad con la práctica pedagógica investigativa debe aplicarla al núcleo familiar en el cual convive, con el desarrollo de alternativas pedagógicas que sirvan como apoyo académico y pactos de convivencia para proteger la vida y la integralidad de los suyos.

Al tomar en cuenta que dentro de la política de formación docente se ha considerado la investigación como uno de los pilares fundamentales del quehacer pedagógico de sus egresados, también considera que el proceso 
de indagación y reflexión pedagógica que los estudiantes del Programa de formación complementaria adelantan, tiene unas características particulares, debido a las circunstancias que se viven en tiempos de pandemia, que deben analizarse y revisarse constantemente con los maestros coordinadores de práctica.

Para garantizar el funcionamiento y el cumplimiento de los lineamientos institucionales en la formación de maestros superiores, se insta a los maestros en formación y a sus familias a formar parte activa de este proceso, con implementación, al interior de sus casas, del trabajo colaborativo, la paciencia, responsabilidad y dedicación en cada una de las tareas, que permiten, en medio de las dificultades, continuar con el desarrollo académico establecido.

Referirse a la educación en tiempos de pandemia, nos lleva a repensar la forma de educar, formar, comprender, con la utilización de distintos mecanismos para empezar una educación diferente, donde las herramientas fundamentales han sido las tecnologías de la información, que han permitido trabajar desde las casas de cada estudiante, por lo que se puede hablar de formación a distancia, bajo la orientación del maestro.

La crisis sanitaria cambió el panorama educativo de miles de estudiantes en todo el mundo, por lo que las plataformas digitales se convirtieron en la gran ayuda o herramienta para no perder el año escolar, lo que ha llevado a los docentes a adaptarse a nuevos cambios educativos, en una nueva realidad, que está lejos de cambiar, donde el ingreso a clases presenciales todavía es incierto.

Para muchos docentes, esta nueva realidad representa un verdadero panorama complicado, ya que la mayoría de maestros no cuenta con competencias para una educación online eficiente; esta crisis ha puesto en jaque la forma de educar, puesto que el maestro se siente inseguro y con demasiado stress, que ha llegado a afectar el buen desempeño profesional y la convivencia familiar.

Se debe optar por la utilización de soluciones de alta o débil tecnología, en función del abastecimiento de energía, acceso a internet y de las competencias digitales de docentes y estudiantes; incluso la difusión de cursos a través de emisoras de radio, cadenas de televisión, que pueden responder a las necesidades específicas de cada región o zona rural del país.

Además, es importante crear vínculos entre las escuelas, los padres, los docentes y estudiantes para garantizar las interacciones sociales que 
favorecen las medidas de protección social y responder a los problemas psicosociales, puesto que los estudiantes pueden verse confrontados con situaciones de aislamiento.

En el trabajo que vienen desarrollando los maestros, se busca el desafío de continuar con las prácticas pedagógicas enseñanza-aprendizaje, desde las casas, para que los niños asuman un nuevo reto, en el que impera la desigualdad, en una sociedad sumergida en la angustia, para sostener que nuestra escuela y la relación pedagógica entre docentes y estudiantes son irremplazables.

El llevar la irremplazable escuela a nuestros hogares es un gran desafío, que el maestro debe liderar con los padres de familia, para plasmar en cada temática y actividad la evaluación de los aprendizajes; en cada práctica educativa, es necesario tener en cuenta acciones, aprendizajes, decisiones y alternativas que llevan a resultados positivos frente al desafío de aprender desde sus hogares.

Se deben analizar y valorar los aprendizajes que deja esta situación de encierro, que nunca se había vivido, pero que deja una gran lección de cambio de aprendizaje en cada familia, a pesar de las grandes disparidades que tantas veces marcan una gran diferencia para la formación de nuestros estudiantes.

Enseñar con utilización de los entornos de educación en línea es un proceso que se inicia debido a esta emergencia sanitaria, lo que permite estudiar con utilización de la internet, con el aprendizaje de contenidos y habilidades específicas que hoy propone la escuela; enseñar en un entorno en línea es diferente a la docencia tradicional; se requiere formar docentes capaces de realizar también la tarea docente en línea; el maestro debe crear condiciones de aprendizaje, producir conocimiento pedagógico, investigar dentro del aula y ser un motivador de afecto y cariño para sus estudiantes.

Hoy, la escuela tiene que tomar rumbos distintos en cuanto a la forma de enseñar y orientar sus conocimientos; debe ser la formadora, donde el maestro asume su responsabilidad a través de experiencias online, videos, videollamadas, plataformas virtuales, cartas escritas a mano en las actividades que se entregan, lo que permite que circule el afecto, el abrazo en palabras, que invite al intercambio y la unión familiar.

La educación en Colombia debe responder a las necesidades del contexto, donde los padres regañen, castiguen y maltraten menos; aprovechar la oportunidad para que los padres dialoguen y compartan 
con sus hijos, jugar con ellos, orientarlos en sus trabajos y actividades; la responsabilidad del maestro es cualificarse pedagógicamente y formarse en las nuevas competencias digitales, que ayudarán a repensar la educación, evaluar los procesos formativos y llevar a cabo el seguimiento del desarrollo académico y socioafectivo de cada uno de sus estudiantes.

Ante las vivencias que se establecen de manera diaria, es importante preguntar: ¿qué están sintiendo?, ¿qué rescatan de la situación que están viviendo?, ¿qué es lo que más echan de menos de la escuela?, ¿cuál es el papel asumido por sus padres?, ¿sus maestros han sido su apoyo constante?, ¿la tecnología ha servido como enlace de comunicación?

Para estructurar un sistema que, en verdad, asegure una educación, según Guevara (2008), se debe tener en cuenta que el Sistema educativo señala gran parte de la responsabilidad del proceso de aprendizaje a los docentes, los cuales deben asumir diversos roles dentro de su práctica profesional. De esta forma, la función docente va más allá del conocimiento. El ejercicio de la docencia abarca el ámbito académico, social y político, por considerarse actualmente a la educación como un ente inseparable de la vida. Así mismo, el docente conoce que él es un orientador que proporciona ayuda al educando, facilita estrategias que contribuyan a la adquisición de conocimientos nuevos; debe ser alguien que genere en el ser humano bienestar, armonía y calidad de vida.

Pese a la situación actual, la educación ha sufrido grandes cambios: uno de ellos es el papel del docente en la educación; ahora, es con la estrategia de la educación a distancia, la que destaca su función de mediador del proceso educativo de sus estudiantes, para lo cual tiene que planificar el desarrollo de las actividades y tareas que se llevarán a cabo en entornos a distancia, motivar y facilitar experiencias de aprendizaje con utilización de actividades virtuales, así como promover la retroalimentación entre profesores y estudiantes vía online, por lo cual, según García (2020),

el maestro como orientador debe preocuparse por maximizar las oportunidades de aprendizaje de todos y cada uno de los estudiantes, reconocer y trabajar con dificultades de carácter cognitivo, social y/o emocional, que pudieran afectar al proceso de aprendizaje de los estudiantes.

El docente debe identificar cuáles son las necesidades educativas que se les presentan no solo a los estudiantes, sino al aula de clase; su entorno, 
qué virtudes y destrezas tiene el educando; sus ventajas y desventajas en el ámbito educativo, pero no solo en éste, sino en el social, económico, cultural, en cada sector que le aporta un desarrollo humano.

Por tanto, el maestro orientador debe cumplir un papel importante en tiempos de pandemia, debe tener en cuenta y entender el contexto en que vive el niño, pues no todos cuentan con las mismas posibilidades en cuanto a la conectividad; es necesario que cada estudiante reciba la misma prioridad, sin importar sus características. La labor del buen maestro está en juego, ¿por qué? Porque el buen maestro buscará los diferentes recursos, metodologías y estrategias para que cada uno de los estudiantes aprenda y reciba el material y las adecuaciones académicas necesarias, que inducen al niño para que sea autónomo; el maestro será quien aporte en el proceso de formación, con el objetivo de llevar a que el estudiante fuera una persona crítica, analítica, reflexiva, capaz de cambiar la sociedad; que transmita una forma diferente de pensar a las personas que se encuentran a su alrededor, para que las proyecte hacia una visión más allá de lo cotidiano.

El guía docente es una figura capacitada para trabajar por la escuela y mejorarla, lo cual le lleva a ser partícipe de la labor del liderazgo, y es que pensar en el liderazgo, como un aspecto constitutivo de la identidad de un orientador, no se centra tanto en temas de habilidad, sino en una forma diferente de enfrentar los trabajos en los centros, según lo señala Guerrero de la Cruz, (2016). La habilidad, en el momento de desarrollar la clase, es importante, pero se deben abordar los trabajos de forma diferente, para que los estudiantes se sientan a gusto y aprendan de manera significativa temas de su interés.

El liderazgo del maestro orientador no se ve reflejado en los títulos educativos que hubiera obtenido en el transcurso de su formación pedagógica, sino en el compromiso y capacidad que tiene para enfrentar las diferentes problemáticas dentro y fuera del aula de clase; el docente que se vive cuestionando el ¿cómo? y ¿por qué? de las situaciones, aborda todas las posibilidades para que así pueda encontrar las soluciones pertinentes y lograr el mejoramiento de su institución.

Por tanto, se puede concluir que el papel que cumple el maestro es muy importante para el desarrollo de una buena educación de calidad en los educandos, ya que tiene que enfrentar nuevos retos para que los estudiantes alcancen un aprendizaje significativo; aun no estando en un aula de clase, el maestro debe manejar diferentes herramientas, que le permitan facilitar 
el aprendizaje a sus educandos para constituir así un vínculo maestroestudiante que ayudará a enriquecer este proceso.

\section{Resultados}

Las Normales, en Colombia, construyen un proyecto académico para formar un maestro de la más alta calidad científica y ética, proyecto en el que la pedagogía, como saber fundante, se constituye en fuente y vector que potencia la formación de un sujeto portador de un saber que integra la comprensión de la educabilidad y la enseñabilidad, a la vez que contribuye a la construcción de una cultura de la convivencia, del pluralismo, de la solidaridad, de la participación y de la preservación del medio ambiente, con creación de mecanismos para la formación de una cultura internacional y de una justicia social, que fortalece la investigación de tal manera que el educador fundamente en ella su ejercicio profesional y, en consecuencia, sienta la urgencia de consolidar el trabajo de grupos y líneas de investigación.

El maestro normalista tiene mucha claridad en cuanto a su formación y desempeño dentro y fuera del aula; es muy consciente de que su trabajo tiene mucha relevancia y expectativas para demostrar qué capacidades teóricas influyen en la orientación de sus niños y cómo su enseñanza es la base para adquirir nuevos conocimientos.

La formación complementaria es otro de los nuevos compromisos que asumen las Normales, donde se prepara un maestro acorde con las necesidades educativas de las comunidades rurales y urbanas. En su práctica cotidiana, el maestro se enfrenta a sus estudiantes y sus expectativas, tan disímiles como el número de aprendices en el aula, y se compromete con las particularidades de cada uno. No solo el saber de cada estudiante es diverso, sino sus modos y fuentes de motivación hacia el aprendizaje.

El lugar que actualmente tiene el maestro le asigna la labor definitiva de formar a las jóvenes generaciones, razón que pone al orden del día la función social de sus acciones. Sabemos que esta responsabilidad social se ha tornado compleja, por cuanto requiere que se apropie de los conocimientos de un campo disciplinar y sea capaz de enfrentarse a los retos que exige una sociedad como la de hoy.

Cuando se piensa que un maestro es un formador de seres humanos y que muchas veces es el profesional que pasa más tiempo con los niños y jóvenes, se evidencia la importancia social de su trabajo y las diversas 
responsabilidades de su profesión. El maestro contemporáneo se enfrenta a retos que le impone su disciplina, y a otros que le demanda la sociedad. Hoy en día, requiere de habilidades diferentes para solucionar con creatividad los primeros, y participar así en la solución de los segundos, pero, en la actualidad, con toda la responsabilidad que se ha asumido con la formación de maestros, es conveniente analizar y formularse estas preguntas:

¿Estamos preparados para formar un maestro con todas las cualidades y valores que hoy necesita la sociedad?

¿A los maestros se los prepara con un conocimiento fundamentado en la praxis?

¿Los maestros orientan las didácticas y la práctica pedagógica investigativa en todas las áreas básicas?

¿La tecnología orienta y lleva a que el maestro asuma los retos de los avances científicos e informáticos?

¿Las Escuelas Normales cuentan con materiales y dotación de recursos adecuados para la formación de los maestros superiores?

¿Los normalistas superiores cuentan con el apoyo del Ministerio de Educación para continuar sus estudios como Licenciados?

¿Hoy, la educación en Colombia debe estructurarse apuntando a una calidad educativa?, ¿las Normales cuentan con el apoyo del MEN, para lograr estos propósitos?

¿Los docentes que hoy laboran en las Escuelas Normales del país, en el programa de formación complementaria, cuentan con estímulos económicos para asumir su trabajo con responsabilidad y calidad en la formación de los nuevos maestros?

Estos interrogantes contribuyen a fortalecer y entender la importancia de las Escuelas Normales que, desde 1821, han venido cumpliendo un gran papel y poco a poco se han transformado y actualizado debido a las exigencias del siglo XXI.

El compromiso es la reestructuración de la Normal, porque el reto del siglo XXI lo impone, pero se sabe también que las Normales tienen una gran misión, que es la de formar maestros para una nueva sociedad, especialmente en relación con los niños y los jóvenes y, cuando se refiere a ellos, no se cree que por eso es más fácil la formación del normalista; es exactamente todo lo contrario.

El programa de formación complementaria busca que los docentes diseñen y apliquen estrategias pedagógicas innovadoras que incidan en el 
desarrollo de las competencias y en el mejoramiento de la calidad de la educación. El desarrollo profesional de los docentes y directivos del país apunta a formar un educador de la más alta calidad científica y ética; a desarrollar la teoría y la práctica pedagógica como parte fundamental del saber del educador; a fortalecer la investigación en el campo pedagógico y en el saber específico; y a preparar educadores para los diferentes niveles y formas de prestación del servicio educativo.

Esto implica desarrollar acciones y estrategias, tanto en la formación permanente o en el servicio de los docentes, orientada a la actualización profesional y al perfeccionamiento de la enseñanza, tanto como en la formación inicial ofrecida por las Facultades de Educación y las ENS. La formación inicial del docente se convierte en la base y pilar del Sistema educativo en la medida en que prepara los profesionales para el ejercicio de la docencia y el fortalecimiento y cualificación de estos programas permitirá tener docentes altamente preparados para asumir los retos y compromisos que requiere el desarrollo social y local.

En este sentido, las ENS se constituyen en un foco importante de atención por ser instituciones educativas formadoras de maestros para la educación preescolar y básica primaria y por el rol protagónico que a nivel regional y nacional han tenido en la Historia de la Educación en nuestro país.

El papel de las ENS es importante y goza de gran reconocimiento por parte de otros establecimientos, que las toman como referente y modelo en sus procesos, no solo para la formación de los docentes, sino también como institución educativa en sí misma, razón por la cual se torna importante acompañarlas, al fortalecerlas y consolidarlas como ejemplos para la región y el país.

Es importante tener en cuenta que la vida de la escuela supone discernimiento, reflexión y toma de decisiones para los estudiantes, donde la pedagogía, los valores y criterios relacionados con la formación de maestros superiores se anclan a los contextos escolares específicos en el trajinar del día a día, donde el trabajo implica relaciones con seres humanos, lo que se manifiesta en una dimensión ética basada en los actos sociales cotidianos. 


\section{Conclusiones}

Las Escuelas Normales asumen la transversalidad como una visión conjunta de las disciplinas, áreas o proyectos, conexas entre sí y con relaciones definidas, a fin de que sus actividades y procesos no se produzcan en forma aislada, dispersa y fraccionada; dentro de ella, la estrategia curricular se orienta a través del reconocimiento de los principios pedagógicos como la educabilidad, enseñabilidad, pedagogía y contextos que los direccionan por un eje problémico, que se materializa en la ejecución teórico-práctica de las temáticas, problemas, casos y proyectos que se generan en el Plan de estudios.

Las ENS vienen demostrando que sus doscientos años de trayectoria formativa y pedagógica han sido el semillero de maestros comprometidos con la educación en lo rural, con fortalecimiento de lo académico y el desempeño de valores para consolidar una sociedad más justa y equitativa, que vele por los principios de unidad e integración en cada comunidad.

Es necesaria una apropiación de la cultura escolar, en donde los aprendices de maestros afrontan, comparten y buscan diferentes estrategias que los asimilan con el significado de ser maestro, lo que demuestran a través de la práctica y el reconocimiento del terreno de trabajo que los lleva a encontrar los principios pedagógicos necesarios en la cultura escolar.

Las ENS deben garantizar a Colombia un nuevo profesional de la educación, con el dominio de un saber fundante, como lo es la pedagogía; un saber específico, desde una concepción humanística, fortalecido por su praxis pedagógica; es decir, por su capacidad reflexiva, que lleva a que la investigación formativa fuera una herramienta que le permita desarrollar autonomía, autorrealización y lo caracterice por la continua autoformación pedagógica.

El maestro nace y se hace, crece y decrece, madura y fenece; la vida del maestro es un transcurrir divergente entre su aspiración exitosa y una realidad que algunas veces se muestra desilusionante, pero planteada y replanteada para ejercitar el sacrificio y probar la perseverancia que lo hace una persona comprometida con su labor y desempeño personal.

Las competencias profesionales del educador se enfocan como el conjunto de conocimientos, habilidades, capacidades, actitudes y valores necesarios para desarrollar una docencia de calidad, que abarca lo que debe saber, saber hacer y saber ser del profesorado, para abordar los problemas de la enseñanza y el aprendizaje. 
Las Escuelas Normales necesitan del apoyo constante del MEN para estructurar una educación de calidad, que apunte a la solución de las necesidades de las poblaciones tanto rurales como urbanas, de un maestro que cumpla con su papel y que sea un protagonista mediante su liderazgo.

El maestro normalista tiene mucha claridad en cuanto a su formación y desempeño dentro y fuera del aula; es muy consciente de que su trabajo tiene mucha relevancia y expectativas para demostrar qué capacidades teóricas influyen en la orientación de sus niños y cómo su enseñanza es la base para adquirir nuevos conocimientos.

\section{Referencias}

Álvarez Gallego, Alejandro. Y la escuela se hizo necesaria: en busca del sentido actual de la escuela. Bogotá: Magisterio, 1995.

Ávalos, Beatrice. "El nuevo profesionalismo: formación docente inicial y continua", En El oficio del docente. Vocación, trabajo y profesión en el siglo XXI, compilado por Tenti Fanfani, Emilio. Buenos Aires: Siglo XXI, 2006. 209-238.

Bohórquez Casallas, Luis Antonio. La evolución educativa en Colombia. Bogotá: Cultural Colombiana, 1956.

Congreso de la República. Ley 115 de febrero 8 de 1994. https://www. mineducacion.gov.co/1621/articles-85906_archivo_pdf.pdf

Consejo de Acreditación de las Escuelas Normales, Ministerio de Educación Nacional. Formación de maestros: Elementos para el debate". Bogotá: MENCAENS, 1999. https://www.mineducacion.gov.co/1621/articles-85742_ Archivo_pdfl.pdf

Delors, Jacques. La educación encierra un tesoro. México: Unesco, 1996.

Delors, J., et al. Informe a la Unesco de la comisión internacional sobre la educación para el siglo XXI: La educación encierra un tesoro. Madrid: Santillana, Ediciones Unesco, 1996). 91-103.

Delval, Juan. Aprender en la vida y en la escuela. Madrid: Morata, 2000. 
Ferry, Gilles. El trayecto de la formación. El enseñante entre la teoría y la práctica. México: Paidós, 1990.

Figueroa, Claudia, y Londoño Ramos, Carlos. "De la Escuela Normal Superior de Colombia al Instituto Caro y Cuervo. Un aporte histórico cultural a la educación colombiana (1936-1951)". Revista Historia de la Educación Colombiana. Vol. 18. $\mathrm{N}^{\mathrm{o}} 18$ (2015): 71-95. https://doi.org/10.22267/ rhec. 151818.29

Foucault, Michel. La pedagogía y la educación. Pensar de otro modo. Bogotá: Delfin, 2005.

García, Carlos Marcelo y Vaillant, Denise. Desarrollo profesional docente. ¿Cómo se aprende a enseñar? Madrid: Narcea Ediciones, 2010.

Gómez, A. "El Maestro". Trabajo para optar el título de institutor, Escuela Normal de Medellín, mecanografiado, 1940.

González Ayala, Libia Isabel y Tibaduiza Vargas, Herver Darío. "El movimiento pedagógico en Colombia y la subjetividad del maestro a 20 años de la Ley general de educación: Grupo de Historia de la Práctica Pedagógica". Tesis de maestría, en Pontificia Universidad Javeriana, 2015. https://repository.javeriana.edu.co/bitstream/ handle/10554/18669/ GonzalezAyalaLibiaIsabel2015.pdf? sequence $=1 \&$ isAllowed $=y$

Guerrero de la Cruz, J. A. "Percepciones de los estudiantes sobre el liderazgo ejercido por sus representantes estudiantiles en una escuela pública de alto rendimiento de Lima". Trabajo de maestría en Pontificia Universidad Católica del Perú, 2016. file:///D:/descargas/GUERRERO_DE_LA_ CRUZ_JESSICA_PERCEPCIONES.pdf

Guevara, Yolanda. Escuela: del fracaso al éxito. México: Editorial Pax,2008.

Laverde Ospina, Alfredo. Panorama continental de la intervención cultural y los efectos políticos de la práctica crítica. Caso especial de Hernando Téllez y José Lins do Rego. Revista Cuadernos de Literatura del Caribe e Hispanoamérica. N$^{\circ} 29$ (2019): 171-190.

Martínez Boom, Alberto y Noriega Castro, Carlos. Crónica del desarraigo. Historia del maestro en Colombia. Bogotá: Magisterio, 1989. 
Ministerio de Educación Nacional. Hacia un sistema nacional de formación de educadores. Bogotá: Enlace Editores, 1998.

Ministerio de Educación Nacional. Plan Decenal de Educación, Colombia, 19962005. https://www.mineducacion. gov.co/1621/articles-85242_archivo_ pdf.pdf

Ocampo López, Javier. Julio Sieber: fundador de un nuevo modelo de pedagogía en Colombia. Tunja: UPTC, 1992.

Presidencia de la República. Decreto 4790 de 2008 (diciembre 19). https://www. mineducacion.gov.co/1621/articles-179246_archivo_pdf.pdf

Quintero Trujillo, Daniel. La Escuela Normal Superior. Proyecto pedagógico $y$ social en desarrollo. Oportunidad de cambio. Tunja: Boyacense de impresores, 1996.

Quintero Timaná, Diego. "Formación docente en Educación Para La Paz, en la Escuela Normal Superior del Municipio de La Cruz - Nariño". Revista Historia de la Educación Colombiana. Vol. 24. No 24 (2020). https://doi. org/10.22267/ rhec.202424.73

Sáenz Obregón, Javier et al. Mirar la infancia: pedagogía, moral y modernidad en Colombia, 1903-1946. Bogotá: Colciencias, 1997.

Torres, Rosa María. "La responsabilidad social de impulsar, propiciary defender las políticas de profesionalización plena de los maestros", en Profesionalización docente, Cuaderno de trabajo $N^{\circ}$ 8, Cumbre Internacional de Educación, México: CEA-UNESCO, 1997.

Triana Ramírez, Alba Nidia. "Escuela normal rural, agropecuaria y de campesinas en Colombia: 1934-1974". Revista Historia de la Educación Colombiana. Vol. 13. No 13 (2010): 201-230. https://revistas.udenar.edu.co/index.php/ rhec/article/view/724/889

Triana, Alba. "Formación de maestros rurales colombianos 1946-1994". Revista historia de la educación latinoamericana. Vol. 14. Nº 18 (2012): 93-118.

Vicepresidencia de la República. Decreto Número 491 de 1904 (junio 3). https:// www.mineducacion.gov.co/1759/ articles-102515_archivo_pdf.pdf 
Zuluaga, Olga Lucía. "Las Escuelas Normales en Colombia". Revista Educación y Pedagogía. $\mathrm{N}^{\mathrm{o}}$ 12-23 (1996): 263-278.

Zuluaga, Olga Lucía et al. El saber pedagógico: experiencias y conceptualizaciones. Ponencia presentada en el Simposio Colombo-Alemán de pedagogía comparada, Medellín, 1999.

Zuluaga, Olga Lucía et al. "Pedagogía, didáctica y enseñanza". Educación y Cultura. No 14 (1998): 10-18.

\section{Citar este artículo}

Muñoz Bravo, José Oliden. "Las Escuelas Normales Superiores en Colombia: doscientos años de historia entre retos y desafíos (1821-2021)". Revista Historia de la Educación Colombiana. Vol. 25 No 25 (2020): 55-93. DOI: https://doi. org/10.22267/rhec.202525.79 